\title{
Statins and the Kidney: Friend or Foe?
}

\author{
Patrick M. Honore Rita Jacobs Inne Hendrickx Elisabeth De Waele \\ Viola Van Gorp Jouke De Regt Herbert D. Spapen \\ ICU Department, Universitair Ziekenhuis Brussel, Vrije Universiteit Brussel, Brussels, Belgium
}

\section{Key Words \\ Statins - Acute kidney injury - Chronic kidney disease . Rhabdomyolysis · Contrast-induced nephropathy . Cardiorenal syndrome $\cdot$ End-stage renal disease}

\begin{abstract}
Statins essentially are cholesterol-lowering drugs that are extensively prescribed for primary and secondary prevention of cardiovascular disease. Compelling evidence suggests that the beneficial effects of statins may not only be due to controlling cholesterol levels but also due to a pleiotropic cholesterol-independent anti-inflammatory, antioxidant, endothelial-protective and plaque-stabilizing activity. Along this line, statins may also exert acute and long-term effects on renal function. We present a narrative literature review that summarizes arguments in favour or against the preventive and/or therapeutic use of statins in kidney-related diseases or complications. We also highlight the ongoing controversy regarding statin therapy in chronic and endstage kidney disease.

(C) 2016 S. Karger AG, Basel
\end{abstract}

\section{Introduction}

Statins are 3-hydroxy-3-methyl-glutaryl-coenzyme A reductase inhibitors and constitute the first-line drug treatment if exercise and a low-fat diet fail to correct hypercholesterolaemia. In this manner, statins substantially contribute to reduce morbidity and mortality in patients at the highest risk of cardiovascular events [1]. All available statins have similar pharmacology, established efficacy in terms of a dose-dependent beneficial effect on plasma cholesterol concentrations, and a comparable range and severity of adverse events. Atorvastatin and rosuvastatin are drugs with high cholesterol-lowering efficacy as compared with lovastatin, simvastatin, pravastatin, and fluvastatin, which have less cholesterol-lowering potency.

Apart from an intrinsic cholesterol-lowering effect, statins also exhibit anti-inflammatory, antioxidant, and plaque-stabilizing capacities that act in concert to prevent other than cardiovascular damage $[1,2]$. In particular, statins may affect the kidneys via cholesterol-related and - unrelated mechanisms resulting in potential acute and long-term benefit on renal function $[2,3]$.

We reviewed the literature on statin use for the prevention and treatment of various acute or chronic kidney(-related) disorders. Statins are highlighted as a novel therapeutic approach with reference to potential beneficial or harmful effects.

\section{Arguments in Favor of Statin Use}

\section{Prevention of Acute Kidney Injury after Cardiac}

Surgery

Acute kidney injury (AKI) complicating cardiac surgery is often multifactorial leaving the precise impact of

\section{KARGER}

(C) 2016 S. Karger AG, Basel

E-Mail karger@karger.com

www.karger.com/bpu
Patrick Honore, $\mathrm{MD}, \mathrm{PhD}, \mathrm{FCCM}$

Professor of Intensive Care Medicine, Co-Director of ICU Research

ICU Department, UZ Brussel, VUB University

101, Laarbeeklaan, Jette, BE-1090 Brussels (Belgium)

E-Mail Patrick.Honore@az.vub.ac.be 
Table 1. Statin treatment and post-cardiac surgery AKI

\begin{tabular}{|c|c|c|c|c|}
\hline Author (year) & Study design & $\begin{array}{l}\text { Patients } \\
\text { included, } \mathrm{n}\end{array}$ & Effect on AKI & Mortality \\
\hline Huffmyer et al. [5], 2009 & Observational & 1,557 & Less need for RRT & Decreased \\
\hline Virani et al. [8], 2010 & Observational & 3,001 & Reduced AKI incidence & No effect \\
\hline Argalious et al. [9], 2010 & Observational & 10,648 & No effect & No effect \\
\hline Wang et al. [12], 2015 & $\begin{array}{l}\text { Meta-analysis and } \\
\text { meta-regression }\end{array}$ & 59,777 & Reduced AKI incidence & No effect \\
\hline Zheng et al. [13], 2016 & $\begin{array}{l}\text { Randomized, } \\
\text { placebo-controlled }\end{array}$ & 1,922 & Higher incidence of AKI & No effect \\
\hline
\end{tabular}

AKI, acute kidney injury; RRT, renal replacement therapy; CKD, chronic kidney disease.

statins open to speculation $[4,5]$. Statins probably act by inhibiting postoperative inflammatory processes [3]. Compared with statin-naive subjects, patients taking statins indeed had reduced levels of circulating C-reactive protein, tumour necrosis factor alpha, myeloperoxidase, and pro-inflammatory interleukin (IL)-1, IL-6, and IL-8 and higher concentrations of the anti-inflammatory IL-10 [6]. In addition, many other factors such as concomitant disease (e.g. presence of sepsis), perioperative complications (e.g. shock), concomitant potential nephrotoxic medication, type of surgical intervention, and preexisting chronic kidney disease (CKD) must be considered. Cardiac surgery patients may react differently to the type and dose of the statin. For example, statins of high potency have been shown to increase the risk of AKI in a general patient population, whereas corresponding doses of these statins in cardiac surgery patients exhibited renal protective effects [7]. Observational studies on renal protection of preoperative statin use in cardiac surgery patients either demonstrated a decreased incidence of postoperative renal insufficiency [8] or reported no benefit [9-11]. A meta-analysis and meta-regression of almost 60,000 patients showed a $13 \%$ reduction of postoperative AKI in patients who received preoperative statin treatment [12]. Three randomized controlled trials (RCTs) recently reported the effects of statin treatment on kidney function in cardiac surgery patients. Zheng et al. [13] studied rosuvastatin vs. placebo in 1,922 patients.
As part of secondary outcome endpoints, an increased incidence of AKI at $48 \mathrm{~h}$ (24.7 vs. $19.3 \% ; p=0.005)$ was observed in the statin group, most of the cases being Kidney Disease Improving Global Outcome stages 1 and 2 [13]. Billings et al. [14] randomly allocated 615 patients (199 statin-naive patients and 416 patients already on statin therapy) to receive high-dose atorvastatin or matching placebo. Among all participants, AKI occurred in $20.8 \%$ in the atorvastatin and in $19.5 \%$ in the placebo group. However, statin-naive subjects, and particularly those with underlying CKD, developed more AKI [14]. Finally, Park et al. [15] compared high-dose atorvastatin with placebo treatment in 200 statin-naive patients undergoing elective valvular heart surgery. Despite better preoperative hemodynamics in the statin group, no statin-related difference in the incidence of AKI within $48 \mathrm{~h}$ after surgery and no effect on markers of kidney injury and inflammation could be demonstrated [15]. Studies that assessed the effect of statin treatment on postcardiac surgery AKI are summarized in Table 1.

\section{Prevention of AKI after Major Non-Cardiac Surgery}

A retrospective analysis of the electronic records of 57,246 patients who underwent elective non-cardiac surgery failed to show that preoperative statin therapy in doses routinely used to treat hypercholesterolemia changed the incidence of AKI, postoperative dialysis, or hospital mortality [16]. Pan et al. [17] systematically re- 
viewed and analyzed all studies on the association between preoperative statin treatment and postoperative AKI in patients undergoing major surgery. When all studies are considered together, preoperative statin therapy was associated with a significant risk reduction for cumulative AKI and for AKI requiring renal replacement therapy. However, this protective effect was lost when restricting the analysis to RCTs only [13-15].

\section{Prevention of Contrast-Induced Nephropathy}

Exposure to iodinated contrast during coronary angiography and associated coronary interventions may cause acute and persistent worsening of kidney function and is associated with increased mortality. Advanced age, diabetes, congestive heart failure, CKD, hemodynamic instability, and type and volume of contrast may all precipitate the development of contrast-induced nephropathy (CIN) [18]. Previous research accentuated that initiating adequate intravenous hydration with iso-osmolar crystalloids and limiting the amount of low-osmolar and isoosmolar contrast are crucial actions for preventing CIN. Several trials in various clinical conditions, including acute coronary syndromes, examined the effect of different types of statins, high- versus low-dose statins and loading versus chronic dosing of statins. In general, pretreatment with statins decreased the occurrence of CIN as compared with placebo. Statin efficacy at preventing CIN was dose- but not product-dependent and higher in patients with acute coronary syndromes and underlying chronic heart or kidney disease. High doses of high-efficacy statins (40-60 mg atorvastatin) may be more effective [19]. Due to a paucity of controlled data, recommendations on duration or type of chronic statin pre-treatment cannot be made. A recent meta-analysis confirmed that short-term, pre-procedural, intensive statin treatment significantly reduced the incidence of CIN in patients with acute coronary syndromes undergoing coronary angiography and percutaneous coronary intervention [20].

\section{Attenuation of the Cardiorenal Syndrome}

Important bidirectional interactions exist between heart and kidney disease. Acute or chronic dysfunction of the heart or kidneys can induce acute or chronic dysfunction in the other organ [21]. For instance, patients with heart failure with a deteriorating glomerular filtration rate have higher mortality. Inversely, patients with CKD have an increased risk of heart failure, which is responsible for up to $50 \%$ mortality. This "vicious liaison" is known as the cardiorenal syndrome (CRS). Oxidative

Statins and the Kidney: Friend or Foe? stress, endothelial dysfunction, and vascular inflammation are pathophysiological factors that are strongly related to the CRS. The pleiotropic effects of statins on cardiovascular processes, in particular their anti-inflammatory/antioxidant potential and capacity to improve nitric oxide bioavailability, support a benefit on the progression of chronic kidney and heart failure [22].

\section{Reduction of Major Cardiovascular Events and Mortality in CKD}

Cardiovascular disease is the most frequent cause of premature death in early stage CKD. A recent Cochrane review found that statin therapy consistently prevented major cardiovascular events and lowered mortality in patients with CKD not requiring dialysis and without cardiovascular disease at baseline [23]. Statin-related effects on stroke and progression of CKD were less evident [23]. However, high-efficacy statin therapy (atorvastatin $80 \mathrm{mg}$ or rosuvastatin $20 / 40 \mathrm{mg}$ ) was associated with a significant decrease of the risk of stroke in patients with CKD [24]. Few trials reported data on individual adverse events leaving doubt on the safety of chronic statin treatment in CKD [25].

\section{Preventing Aminoglycoside Toxicity}

The pleiotropic properties of statins, though theoretically promising for preventing aminoglycoside toxicity, have only been explored in experimental settings. Ozbek et al. [26] studied the effect of atorvastatin on gentamicininduced nephrotoxicity in rats. Gentamycin infusion markedly reduced kidney function, increased oxidative stress, and was associated with tubular necrosis especially in the renal cortex. Renal function and tissue oxidative stress parameters normalized and tubular necrosis was attenuated in atorvastatin-treated animals. Atorvastatin reduced expressions of mitogen-activated protein kinase, nuclear factor kappa $B$, and inducible nitric oxide synthase confirming a statin-mediated anti-inflammatory and anti-oxidant activity. In a similar rodent model, simvastatin was found to improve gentamicin-induced changes in renal histopathology and function in a dosedependent fashion [27].

\section{Arguments Against Statin Use}

\section{Uncertain or Undesirable Effects on Kidney Function}

A large retrospective cohort study comparing longterm statin users with a matched group of nonusers found an association between statin treatment and an increased 
incidence of acute and chronic renal disease [28]. A recently published systematic review and meta-analysis including 143,888 adult patients showed that statins did not prevent AKI, modestly decreased proteinuria, and attenuated the decline in glomerular filtration rate only in adult patients not receiving dialysis [29].

Compared with low-efficacy drugs, treatment with high-efficacy statins has been associated with a $13 \%$ increased hazard for developing severe renal failure, which remained consistent across specific populations at risk (ischaemic heart disease, diabetes, and CKD) [30].

\section{Increased Risk for Rhabdomyolysis in CKD}

Statins are associated with skeletal muscle complaints, ranging from mild serum creatine kinase elevations and myalgia to severe muscle weakness, muscle cramps, myositis and rhabdomyolysis [31]. Among others, CKD is a common risk factor for the development of statin-induced myopathy. Patients with CKD may become more prone to this invalidating and potential life-threatening complication when other significant risk factors (e.g., advanced age, female gender, liver dysfunction, and diabetes mellitus) are accumulating.

One case report described acute rhabdomyolysis and purpura fulminans in a patient who had used pravastatin for 3 years and developed CKD [32]. However, the patient was highly aged and had received several hemodialysis sessions prior to presentation.

\section{Induction of Tubulo-Interstitial Nephritis}

Some case studies reported a link between statins and (sub)acute tubulo-interstitial nephritis [33, 34]. Nephritis was biopsy-proven, resolved after discontinuing statin treatment, responded to steroids, and relapsed after rechallenging the patient with a statin. A dose-dependent class effect was suggested but not proven. Statin-induced tubulo-interstitial nephritis is probably underreported because it evolves insidiously in patients who are prone to develop AKI for other reasons (e.g., comorbid conditions such as diabetes and arterial hypertension, concomitant nephrotoxic drug treatment, and so on).

\section{Controversy Regarding Statin Use in CKD}

The effects of statins in patients with CKD remain uncertain. In 2003, the Kidney Disease Outcomes Quality Initiative (KDOQI) dyslipidemia guidelines recommended statin therapy in all patients with $\mathrm{CKD}$, irre- spective of dialysis need, targeting low-density lipoprotein cholesterol (LDL-C) concentration below $100 \mathrm{mg} /$ $\mathrm{dL}$ [35]. A sharp reduction in LDL-C with daily simvastatin plus ezetimibe safely reduced the incidence of major atherosclerotic events but did not slow 5-year kidney disease progression in a wide range of patients with advanced CKD [36]. Moreover, the high-efficacy statins atorvastatin [37] and rosuvastatin [38] substantially lowered LDL-C levels but had no statistically significant effect on cardiovascular death, non-fatal myocardial infarction, and stroke in patients with end-stage renal disease (ESRD; i.e., undergoing permanent hemodialysis). Several studies even observed an unexpected and counterintuitive inverse relationship between cholesterol levels and mortality in ESRD patients $[39,40]$. Cardiovascular disease processes in ESRD patients may evolve differently from those in CKD subjects [41]. In fact, they may be primarily driven by oxidative stress, inflammation, and discrepancies between noxious and protective lipoprotein levels and additionally enhanced by hypertension and arrhythmias. Cholesterol lowering by statins in ESRD not only fails to show a benefit but also potentially exposes patients to statin-related side-effects [42, 43]. In a 2012 update of the KDOQI guidelines, recommendations were revised to lowering LDL-C in all patients with CKD except when dialysis was initiated [42]. Clinicians should decide on an individual patient basis whether or not to initiate statins in ESRD. A statin may be justified for secondary prevention of cardiovascular events, in patients with longer life expectancies, and in non-diabetics [42].

\section{Conclusions}

Large well-conducted RCTs did not demonstrate any benefit of pre- or perioperative statin treatment in patients undergoing various types of cardiac surgery. For unknown reasons, statins may even harm the kidneys in this particular patient population. A potential renal protective effect of preoperative statin therapy after major non-cardiac surgery is suggested by observational studies but not confirmed by RCTs. Statins arguably exert protective effects on the kidney in a general adult population and on the cardiovascular system in patients with CKD who do not require dialysis. Adjunctive therapy with statins can dose-dependently prevent CIN and attenuate the CRS. Whether statins affect stroke risk and progression of CKD is less evident. Statin-related rhabdomyolysis remains a matter of concern. High-efficacy agents may
94

Blood Purif 2017;43:91-96 DOI: $10.1159 / 000453577$
Honore/Jacobs/Hendrickx/De Waele/ Van Gorp/De Regt/Spapen 
harm the kidney in patients with vascular compromise and CKD. Also, statins are relatively contra-indicated in patients with ESRD.

Overall, statins are of undisputed efficacy for treatment of hypercholesterolemia and play a prominent role in primary and secondary prevention of cardiovascular disease. However, there is currently insufficient evidence to recommend the routine use of these agents for kidney protection.

\section{Disclosure Statement}

The authors declare to have no competing interests.

\section{Authors' Contributions}

P.M.H. and H.D.S. designed the paper. All authors participated in drafting the manuscript. All authors have read and approved of the final version.

\section{References}

1 Vaughan CJ, Gotto AM Jr: Update on statins: 2003. Circulation 2004;110:886-892.

2 Bedi O, Dhawan V, Sharma PL, Kumar P: Pleiotropic effects of statins: new therapeutic targets in drug design. Naunyn Schmiedebergs Arch Pharmacol 2016;389:695-712.

3 Teshima CA, Watanabe M, Nakamura SH, Vattimo Mde F: Renoprotective effect of statin: a ischemia-reperfusion animal model. Rev Bras Ter Intensiva 2010;22:245-249.

4 Honore PM, Jacobs R, Hendrickx I, De Waele E, Van Gorp V, Spapen HD: Peri-operative fluid strategy and post-operative acute kidney injury in cardiac surgery patients: any role for pre-operative statin therapy? Crit Care 2015; 19:453.

5 Huffmyer JL, Mauermann WJ, Thiele RH, Ma JZ, Nemergut EC: Preoperative statin administration is associated with lower mortality and decreased need for postoperative hemodialysis in patients undergoing coronary artery bypass graft surgery. J Cardiothorac Vasc Anesth 2009;23:468-473.

6 Garwood S: Statins and cardiac surgery. J Cardiothorac Vasc Anesth 2010;24:909-912.

7 Dormuth CR, Hemmelgarn BR, Paterson JM, James MT, Teare GF, Raymond CB, et al. Use of high potency statins and rates of admission for acute kidney injury: multicenter, retrospective observational analysis of administrative databases. BMJ 2013;346:f880.

8 Virani SS, Nambi V, Polsani VR, Lee VV, Elayda M, Kohsaka S, et al: Preoperative statin therapy decreases risk of postoperative renal insufficiency. Cardiovasc Ther 2010;28:8086.

9 Argalious M, Xu M, Sun Z, Smedira N, Koch CG: Preoperative statin therapy is not associated with a reduced incidence of postoperative acute kidney injury after cardiac surgery. Anesth Analg 2010;111:324-330.

10 Nemati MH, Astaneh B: The effects of preoperative statins on the incidence of postoperative acute kidney injury in patients undergoing cardiac surgeries. Interact Cardiovasc Thorac Surg 2015;21:493-498.

11 Mithani S, Kuskowski M, Slinin Y, Ishani A, McFalls E, Adabag S: Dose-dependent effect of statins on the incidence of acute kidney in- jury after cardiac surgery. Ann Thorac Surg 2011;91:520-525.

12 Wang J, Gu C, Gao M, Yu W, Yu Y: Preoperative statin therapy and renal outcomes after cardiac surgery: a meta-analysis and metaregression of 59,771 patients. Can J Cardiol 2015;31:1051-1060.

13 Zheng Z, Jayaram R, Jiang L, Emberson J, Zhao Y, Li Q, Du J, Guarguagli S, Hill M, Chen Z, Collins R, Casadei B: Perioperative rosuvastatin in cardiac surgery. $\mathrm{N}$ Engl J Med 2016;374:1744-1753.

14 Billings FT 4th, Hendricks PA, Schildcrout JS, Shi Y, Petracek MR, Byrne JG, Brown NJ: High-dose perioperative atorvastatin and acute kidney injury following cardiac surgery: a randomized clinical trial. JAMA 2016;315: 877-888.

15 Park JH, Shim JK, Song JW, Soh S, Kwak YL: Effect of atorvastatin on the incidence of acute kidney injury following valvular heart surgery: a randomized, placebo-controlled trial. Intensive Care Med 2016;42:13981407.

16 Argalious MY, Dalton JE, Sreenivasalu T, O'Hara J, Sessler DI: The association of preoperative statin use and acute kidney injury after noncardiac surgery. Anesth Analg 2013; 117:916-923.

17 Pan SY, Wu VC, Huang TM, Chou HC, Ko WJ, Wu KD, et al; NSARF Group: Effect of preoperative statin therapy on postoperative acute kidney injury in patients undergoing major surgery: systemic review and metaanalysis. Nephrology (Carlton) 2014;19:750763.

18 Chyou AC, Thodge A, Feldman DN, Swaminathan RV: Statins in the prevention of contrast-induced nephropathy. Curr Treat Options Cardiovasc Med 2015;17:375.

19 Fu M, Dai W, Ye Y, Lu Q, He W: High dose of atorvastatin for the treatment of contrastinduced nephropathy after carotid artery stenting. Am J Ther 2015, Epub ahead of print.

20 Marenzi G, Cosentino N, Werba JP, Tedesco CC, Veglia F, Bartorelli AL: A meta-analysis of randomized controlled trials on statins for the prevention of contrast-induced acute kid- ney injury in patients with and without acute coronary syndromes. Int J Cardiol 2015;183: 47-53.

21 Athyros VG, Katsiki N, Tziomalos K, Karagiannis A: Preventing cardio-renal syndrome rather than treating it: could statins play a role? Open Cardiovasc Med J 2011;5:226230

22 Yagi S, Aihara K, Ikeda Y, Akaike M, Sata M, Matsumoto T: Effects of statins on cardiorenal syndrome. Int J Vasc Med 2012;2012. 162545.

23 Palmer SC, Navaneethan SD, Craig JC, Johnson DW, Perkovic V, Hegbrant J, et al: HMG CoA reductase inhibitors (statins) for people with chronic kidney disease not requiring dialysis. Sao Paulo Med J 2015;133:541-542.

24 Castilla-Guerra L, Del Carmen FernandezMoreno M, Colmenero-Camacho MA: Statins in stroke prevention: present and future. Curr Pharm Des 2016;22:4638-4644.

25 Law M, Rudnicka AR: Statin safety: a systematic review. Am J Cardiol 2006;97:52C-60C.

26 Ozbek E, Cekmen M, Ilbey YO, Simsek A, Polat EC, Somay A: Atorvastatin prevents gentamicin-induced renal damage in rats through the inhibition of p38-MAPK and NF-kappaB pathways. Ren Fail 2009;31:382-392.

27 Jabbari M, Rostami Z, Jenabi A, Bahrami A, Mooraki A: Simvastatin ameliorates gentamicin-induced renal injury in rats. Saudi J Kidney Dis Transpl 2011;22:1181-1186.

28 Acharya T, Huang J, Tringali S, Frei CR, Mortensen EM, Mansi IA: Statin use and the risk of kidney disease with long-term followup (8.4-year study). Am J Cardiol 2016;117: 647-655.

29 Su X, Zhang L, Lv J, Wang J, Hou W, Xie X, et al: Effect of statins on kidney disease outcomes: a systematic review and meta-analysis. Am J Kidney Dis 2016;67:881-892.

30 Chung YH, Lee YC, Chang CH, Lin MS, Lin JW, Lai MS: Statins of high versus low cholesterol-lowering efficacy and the development of severe renal failure. Pharmacoepidemiol Drug Saf 2013;22:583-592.

31 Thompson PD, Clarkson P, Karas RH: Statinassociated myopathy. JAMA 2003;289:16811690. 
32 Kato K, Onodera K, Iwasaki Y, Matsuda M, Kawakami T, Higuchi M, et al: Pravastatininduced rhabdomyolysis and purpura fulminans in a patient with chronic renal failure. Int J Surg Case Rep 2015;8C:84-87.

33 Annigeri RA, Mani RM: Acute interstitial nephritis due to statin and its class effect. Indian J Nephrol 2015;25:54-56.

34 van Zyl-Smit R, Firth JC, Duffield M, Marais AD: Renal tubular toxicity of HMG-CoA reductase inhibitors. Nephrol Dial Transplant 2004;19:3176-3179.

35 National Kidney Foundation: KDOQI clinical practice guidelines for managing dyslipidemias in chronic kidney disease. www.kidney. org/professionals/Kdoqi/guidelines_lipids/ index.htm (accessed May 2016).

36 Baigent C, Landray MJ, Reith C, Emberson J, Wheeler DC, Tomson C, et al: The effects of lowering LDL cholesterol with simvastatin plus ezetimibe in patients with chronic kidney disease (Study of Heart and Renal Protection): a randomised placebo-controlled trial. Lancet 2011;377:2181-2192.

37 Wanner C, Krane V, März W, Olschewski M, Mann JF, Ruf G, et al; German Diabetes and Dialysis Study Investigators: Atorvastatin in patients with type 2 diabetes mellitus undergoing hemodialysis. N Engl J Med 2005;353: 238-248.

38 Fellström BC, Jardine AG, Schmieder RE, Holdaas H, Bannister K, Beutler J, et al: Rosuvastatin and cardiovascular events in patients undergoing hemodialysis. N Engl J Med 2009; 360:1395-1407.

39 Lin SY, Lin CL, Hsu WH, Lin CC, Chang CT, Kao CH: Association of statin use and the risk of end-stage renal disease: a nationwide Asian population-based case-control study. Eur J Intern Med 2016;31:68-72.

40 Vaziri ND, Norris KC: Reasons for the lack of salutary effects of cholesterol-lowering interventions in end-stage renal disease populations. Blood Purif 2013;35:31-36.

41 Haynes R, Lewis D, Emberson J, Reith C, Agodoa L, Cass A, et al; SHARP Collaborative Group: Effects of lowering LDL cholesterol on progression of kidney disease. J Am Soc Nephrol 2014;25:1825-1833.

42 National Kidney Foundation: KDOQI clinical practice guideline for diabetes and CKD: 2012 update. Am J Kidney Dis 2012;60:850886.

43 Kim JJ, Langworthy DR, Hennessey EK: Clinical implications of statin therapy in patients undergoing hemodialysis. Am J Health Syst Pharm 2014;71:703-710. 